\title{
Effect of Letrozole on hippocampal let-7 microRNAs and their correlation with working memory and phosphorylated Tau protein level in an Alzheimer's disease rat model
}

\section{Nada Alaa Moustafa ( $\nabla$ namostafa@medicine.zu.edu.eg)}

Zagazig University Faculty of Human Medicine https://orcid.org/0000-0003-2701-208X

\section{Mohammed Abdelhamed El-Sayed}

Zagazig University Faculty of Human Medicine

\section{Somia Hassan Abdallah}

Zagazig University Faculty of Human Medicine

Noha M. Hazem

Mansoura University Faculty of Medicine

Doaa Attia Abdelmoety

Zagazig University Faculty of Human Medicine

\section{Research Article}

Keywords: Letrozole, Let-7 microRNAs, Alzheimer's disease, Tau, Memory

Posted Date: April 26th, 2021

DOI: https://doi.org/10.21203/rs.3.rs-444685/v1

License: (c) (i) This work is licensed under a Creative Commons Attribution 4.0 International License.

Read Full License

Version of Record: A version of this preprint was published at The Egyptian Journal of Neurology, Psychiatry and Neurosurgery on June 3rd, 2022. See the published version at https://doi.org/10.1186/s41983-022-00504-7. 


\section{Abstract}

Let-7 microRNAs may contribute to neurodegeneration, including Alzheimer's disease (AD), but, they were not investigated in Streptozotocin (STZ)-induced AD. Letrozole increases the expression of Let-7 in cell lines, with conflicting evidence regarding its effects on memory. This study examined Let-7 microRNAs in STZ-induced AD, their correlation with memory and hyperphosphorylated Tau ( $p$-Tau) and the effects of Letrozole on them. Seven groups of adult Sprague Dawley rats were used: Intact, Letrozole, Letrozole Vehicle, STZ (with AD induced by intracerebroventricular injection of STZ in artificial CSF), CSF Control, STZ + Letrozole (STZ-L), and CSF + Letrozole Vehicle. Alternation percentage in T-maze was used as a measure of working memory. Let-7a, $b$ and e and $p$-Tau levels in the hippocampus were estimated using qRT-PCR and ELISA, respectively. There were significant decreases in alternation percentage and increase in p-Tau in the STZ, Letrozole and STZ-L groups. Expression levels of all studied microRNAs were significantly elevated in the Letrozole and the $S T Z+L$ groups, with no difference between the two, suggesting that this elevation was due to Letrozole. Negative correlations were found between alternation percentage and the levels of all studied microRNAs, while positive ones were found between $\mathrm{p}$-Tau concentration and the levels of studied microRNAs. These findings support the theory that Letrozole aggravates pre-existing lesions and add to the evidence of Let-7 neurotoxicity.

\section{Introduction}

Alzheimer's disease (AD) is a neurodegenerative condition that causes aging-related cognitive impairment and dementia (Davey, 2017) and accounts for $50-75 \%$ of dementia cases, making it the chief cause of dementia (Lane et al., 2018). It is pathologically characterized by accumulation of beta-amyloid (A $)$ plaques, and neurofibrillary tangles of aggregated hyperphosphorylated Tau protein (Liu et al., 2014).

The role of microRNAs (miRNAs) in numerous diseases is currently being heavily studied. miRNAs are approximately 22-nucleotide long, non-coding RNAs that function as gene expression regulators at the post transcriptional level. The Let-7 miRNAs are conserved in multiple species, and are abundantly expressed in the brain (Lee et al., 2016; Derkow et al., 2018). Let-7 miRNAs play roles in cellular differentiation, tumor suppression and neurodegeneration/ neurotoxicity (Lehmann et al., 2012; Shamsuzzama et al., 2016 and Gu et al., 2017). Various members of the Let-7 family were found to be differentially expressed in the cerebrospinal fluid of AD patients (Derkow et al., 2018).

Up to our current knowledge, levels of Let-7 miRNAs were not previously investigated in a Streptozotocin (STZ)-induced AD model, neither was the effect of Let-7 modulation on the memory of the animals in such model.

Multiple drugs were found to increase the expression of Let-7 in various cell lines (Lozier et al., 2015; Francess et al., 2018), an example of which is Letrozole (Shibahara et al., 2012; Cho et al., 2016), which is a potent aromatase inhibitors with an experimental evidence documenting its high permeability across the blood brain barrier (BBB) (Dave et al., 2013). 
Memory changes are somewhat a common complaint in patients treated with Letrozole, however, there are several conflicting studies examining the possible effects of aromatase inhibitors on memory. Some studies have shown that Letrozole administration resulted in memory impairment (Nayebi, Pourrabi and Hossini, 2014; Zameer and Vohora, 2017), while other studies have shown that Letrozole improved the acquisition of working memory and that inhibition of brain estrogen synthesis may have beneficial effects on spatial memory (Alejandre-Gomez, Garcia-Segura and Gonzalez-Burgos, 2007; Aydin et al., 2008).

Another question arises of whether the memory impairments observed with Letrozole treatment occur because of neurosteroidal deficits, or they become exacerbated in the presence of an additional insult associated with aging such as pathologic $A \beta$. Evidence of synaptic pathology and changes in mitochondrial morphology was found in hippocampal cultures treated with both Letrozole and $A \beta$, suggesting that Letrozole potentiates the pathological effects of $A \beta$ (Chang et al., 2013).

Therefore, this study was designed to examine Let-7 miRNAs levels in the hippocampi of STZ-induced AD rats, and their possible correlation with memory status and/or phosphorylated Tau levels and assess the effects of Letrozole on the memory and levels of Let-7 miRNAs in animals treated only with Letrozole as well as animals treated with Letrozole on top of having an existing STZ-induced AD, possibly providing an insight into another mechanism by which Letrozole could exert an effect on cognition via microRNA modulation.

\section{Materials And Methods}

\section{Animals and grouping}

A total number of fifty-one adult Sprague Dawley rats of the same age and weighing 150-200 gm., were subjects of this study. Rats were supplied by the animal unit of the Medical Experimental Research Center (MERC), faculty of Medicine, Mansoura University. An ethical approval for this study was obtained from the Institutional Animal Care and Use Committee (IACUC), Zagazig University, in line with the Guide for the Care and Use of Laboratory Animals 8th Edition 2011.

Rats were housed in plastic rodent cages (3-5/cage) under hygienic and environmentally controlled conditions i.e., ambient temperature of $25 \pm 2^{\circ} \mathrm{C}$, and 12-hour light/ 12-hour dark cycle. They were allowed 14 days for acclimatization, during which, and throughout the entire period of the study, they were fed standard commercial rat chow and had free access to food and water.

After the acclimatization, rats were randomly divided into seven groups as follows:

Group 1: Intact Control Group $(\mathrm{n}=6)$ : No procedure or treatment was applied to this group. It served to establish basal levels of studied parameters (Cognitive function, hippocampal phosphorylated Tau level and Let-7a, b, e microRNA levels). 
Group 2: Letrozole Group ( $\mathrm{n}=9$ ): Letrozole (Synthon, Netherlands ) was given at a daily dose of $2.5 \mathrm{mg} / \mathrm{kg}$ (Alejandre-Gomez et al., 2007) by oral gavage (Aydin et al., 2008). Letrozole was dissolved in $0.5 \%$ carboxy methylcellulose (CMC) solution, and was given for 15 days (Zameer and Vohora, 2017).

Group 3: Letrozole Vehicle (LV) Control Group ( $n=6)$ : Rats were given $0.5 \%$ CMC daily, by oral gavage, for 15 days.

Group 4: STZ Group ( $n=9)$ : In this group, sporadic Alzheimer's disease-like state was induced using intracerebroventricular injection (ICV) of $3 \mathrm{mg} / \mathrm{kg}$ of Streptozotocin (Sigma-Aldrich, USA) dissolved in artificial cerebrospinal fluid (aCSF).

Group 5: CSF Control Group $(n=6)$ : Rats were only administrated aCSF via ICV injections.

Group 6: STZ + Letrozole (STZ-L) Group ( $\mathrm{n}=9$ ): In this group, sporadic Alzheimer's disease-like state was induced using ICV injections of $3 \mathrm{mg} / \mathrm{kg}$ of Streptozotocin dissolved in aCSF. Following the surgery, rats were allowed a recovery period of 7 days then, given $2.5 \mathrm{mg} / \mathrm{kg}$ Letrozole by oral gavage, for 15 days.

Group 7: CSF + Letrozole Vehicle (CSF-LV) Control Group $(\mathrm{n}=6)$ : Rats were administrated aCSF via ICV injections, allowed to recover for 7 days after surgery, then given $0.5 \% \mathrm{CMC}$ daily, by oral gavage, for 15 days.

\section{Induction of AD by ICV injection of STZ}

Animals were anesthetized and the general guidelines and steps for stereotaxic surgery were followed as mentioned by Hau and Schapiro, (2002) and Langhans et al., (2016). A single dose of Streptozotocin (3 $\mathrm{mg} / \mathrm{Kg}$ (Mehla et al., 2013)), in $10 \mu \mathrm{L}$ aCSF (119 mM NaCl, $26.2 \mathrm{mM} \mathrm{NaHCO}_{3}, 2.5 \mathrm{mM} \mathrm{KCl}, 1 \mathrm{mM}$ $\mathrm{NaH}_{2} \mathrm{PO}_{4}, 1.3 \mathrm{mM} \mathrm{MgCl}_{2}, 10 \mathrm{mM}$ glucose and $2.5 \mathrm{mM} \mathrm{CaCl}_{2}$ in distilled water, then passed through a 0.22 $\mu \mathrm{m}$ filter to sterilize (Cold spring harbor, 2011)) was injected bilaterally into the lateral ventricles using coordinates according to the rat stereotaxic brain atlas (Paxinos and Watson, 2006), and the Waxholm Rat atlas via the scalable brain atlas (Papp et al., 2014; Bakker et al., 2015; Kjonigsen et al., 2015 and Sergejeva et al., 2015): anteroposterior from bregma (AP) $=-0.9 \mathrm{~mm}$, mediolateral from the midline $(\mathrm{ML})=$ $\pm 1.5 \mathrm{~mm}$ and dorsoventral from the skull $(\mathrm{DV})=3.6 \mathrm{~mm}$. Animal were allowed a week to fully recover prior to administration of any further treatment. Typically, the effects of STZ on memory functions start to manifest 15 days following the injection (Mehla et al., 2013). Hematoxylin and eosin (H\&E) staining of hippocampal sections from representative samples was done to further confirm the presence of neurodegeneration.

\section{Testing of working memory: Spontaneous alternation in a modified T-maze}

A manually-run maze was constructed. The maze design was adapted from Deacon and Rawlins, (2006). No habituation to the maze was allowed, as it is the novelty of the maze that motivates the spontaneous exploration/ alternation. For each rat, one sample trial and five choice runs were performed per day for two days, amounting to a total of 12 trials per rat, and a total of ten possible alternations. A percentage or 
proportion correct choice (alternation) per animal was calculated as follows (Deacon and Rawlins, 2006; Wu et al., 2018):

\section{Animals and grouping}

A total number of fifty-one adult Sprague Dawley rats of the same age and weighing 150-200 gm., were subjects of this study. Rats were supplied by the animal unit of the Medical Experimental Research Center (MERC), faculty of Medicine, Mansoura University. An ethical approval for this study was obtained from the Institutional Animal Care and Use Committee (IACUC), Zagazig University, in line with the Guide for the Care and Use of Laboratory Animals 8th Edition 2011.

Rats were housed in plastic rodent cages (3-5/cage) under hygienic and environmentally controlled conditions i.e., ambient temperature of $25 \pm 2^{\circ} \mathrm{C}$, and 12-hour light/ 12-hour dark cycle. They were allowed 14 days for acclimatization, during which, and throughout the entire period of the study, they were fed standard commercial rat chow and had free access to food and water.

After the acclimatization, rats were randomly divided into seven groups as follows:

Group 1: Intact Control Group ( $\mathrm{n}=6)$ : No procedure or treatment was applied to this group. It served to establish basal levels of studied parameters (Cognitive function, hippocampal phosphorylated Tau level and Let-7a, b, e microRNA levels).

Group 2: Letrozole Group ( $\mathrm{n}=9$ ): Letrozole (Synthon, Netherlands ) was given at a daily dose of $2.5 \mathrm{mg} / \mathrm{kg}$ (Alejandre-Gomez et al., 2007) by oral gavage (Aydin et al., 2008). Letrozole was dissolved in $0.5 \%$ carboxy methylcellulose (CMC) solution, and was given for 15 days (Zameer and Vohora, 2017).

Group 3: Letrozole Vehicle (LV) Control Group ( $n=6)$ : Rats were given $0.5 \%$ CMC daily, by oral gavage, for 15 days.

Group 4: STZ Group (n=9): In this group, sporadic Alzheimer's disease-like state was induced using intracerebroventricular injection (ICV) of $3 \mathrm{mg} / \mathrm{kg}$ of Streptozotocin (Sigma-Aldrich, USA) dissolved in artificial cerebrospinal fluid (aCSF).

Group 5: CSF Control Group $(n=6)$ : Rats were only administrated aCSF via ICV injections.

Group 6: STZ + Letrozole (STZ-L) Group ( $\mathrm{n}=9$ ): In this group, sporadic Alzheimer's disease-like state was induced using ICV injections of $3 \mathrm{mg} / \mathrm{kg}$ of Streptozotocin dissolved in aCSF. Following the surgery, rats were allowed a recovery period of 7 days then, given $2.5 \mathrm{mg} / \mathrm{kg}$ Letrozole by oral gavage, for 15 days.

Group 7: CSF + Letrozole Vehicle (CSF-LV) Control Group $(\mathrm{n}=6)$ : Rats were administrated aCSF via ICV injections, allowed to recover for 7 days after surgery, then given $0.5 \% \mathrm{CMC}$ daily, by oral gavage, for 15 days.

\section{Induction of AD by ICV injection of STZ}


Animals were anesthetized and the general guidelines and steps for stereotaxic surgery were followed as mentioned by Hau and Schapiro, (2002) and Langhans et al., (2016). A single dose of Streptozotocin (3 $\mathrm{mg} / \mathrm{Kg}$ (Mehla et al., 2013)), in $10 \mu \mathrm{L}$ aCSF (119 mM NaCl, $26.2 \mathrm{mM} \mathrm{NaHCO}_{3}, 2.5 \mathrm{mM} \mathrm{KCl}, 1 \mathrm{mM}$ $\mathrm{NaH}_{2} \mathrm{PO}_{4}, 1.3 \mathrm{mM} \mathrm{MgCl}_{2}, 10 \mathrm{mM}$ glucose and $2.5 \mathrm{mM} \mathrm{CaCl}_{2}$ in distilled water, then passed through a 0.22 $\mu \mathrm{m}$ filter to sterilize (Cold spring harbor, 2011)) was injected bilaterally into the lateral ventricles using coordinates according to the rat stereotaxic brain atlas (Paxinos and Watson, 2006), and the Waxholm Rat atlas via the scalable brain atlas (Papp et al., 2014; Bakker et al., 2015; Kjonigsen et al., 2015 and Sergejeva et al., 2015): anteroposterior from bregma (AP) $=-0.9 \mathrm{~mm}$, mediolateral from the midline $(\mathrm{ML})=$ $\pm 1.5 \mathrm{~mm}$ and dorsoventral from the skull $(\mathrm{DV})=3.6 \mathrm{~mm}$. Animal were allowed a week to fully recover prior to administration of any further treatment. Typically, the effects of STZ on memory functions start to manifest 15 days following the injection (Mehla et al., 2013). Hematoxylin and eosin (H\&E) staining of hippocampal sections from representative samples was done to further confirm the presence of neurodegeneration.

\section{Testing of working memory: Spontaneous alternation in a modified T-maze}

A manually-run maze was constructed. The maze design was adapted from Deacon and Rawlins, (2006). No habituation to the maze was allowed, as it is the novelty of the maze that motivates the spontaneous exploration/ alternation. For each rat, one sample trial and five choice runs were performed per day for two days, amounting to a total of 12 trials per rat, and a total of ten possible alternations. A percentage or proportion correct choice (alternation) per animal was calculated as follows (Deacon and Rawlins, 2006; Wu et al., 2018): see formula 1 in the supplementary files.

\section{Biochemical and molecular testing}

Animals were euthanized by cervical dislocation following The University of Texas at Austin (2013) guideline and the brain was immediately removed from the skull and washed with ice cold saline. The hippocampi were rapidly dissected following the method described by Spijker (2011) and weighed. Each

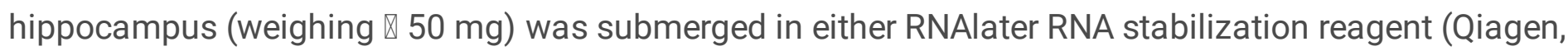
USA, Cat No./ID: 76104), or sterile Phosphate-buffered saline (PBS) and stored at a temperature of $-80^{\circ} \mathrm{C}$ for biochemical analysis (Silva et al., 2004).

Total RNA, including microRNAs, was extracted from the hippocampus using the miRNeasy Mini Kit (Qiagen, USA, Cat No./ID: 217004) following the kit's manual, and the purity and concentration the extracted total RNA were spectrophotometrically determined using a NanoDrop (Desjardins and Conklin, 2010). Reverse transcription (RT) reaction was done for each sample using the TaqMan ${ }^{\text {TM }}$ microRNA reverse transcription kit (Applied biosystems, USA, Cat no.: 4366596) following the kit's manual. A specific TaqMan microRNA assay was used, following the manufacturer's instructions, in qRT-PCR to detect each of the three target microRNAs (Let7a, b and e) as well as U6 small nuclear RNA as an endogenous control (rno-let-7a-5p [Assay ID: 000377], rno-let-7b-5p [Assay ID: 000378], rno-let-7e-5p [Assay ID: 002406] and U6 snRNA [Assay ID: 001973], Applied biosystems, USA, Cat no.: 4427975). Changes of miRNA expression 
were calculated for each of the three tested miRNAs using the $2^{\wedge}(-\Delta \Delta \mathrm{Ct})$ method (Livak and Schmittgen, 2001 and Schmittgen and Livak, 2008).

Rat p-Tau (Ser396) protein ELISA kit (Bioassay technology laboratory, Shanghai, China) was used according to the manufacturer's instructions to measure $p$-Tau concentration in the hippocampus.

\section{Statistical analysis}

The statistical analysis was done using IBM SPSS Statistics for Windows, version 22 (IBM Corp., Armonk, N.Y., USA). For quantitative variables, mean and standard deviation were computed. Median and range were computed in case of data that were not normally distributed (Non-parametric data). One way analysis of variance (ANOVA) test was used for comparison of means of more than two groups in normally distributed data, and Kruskal Wallis test was used in case of data that were not normally distributed. Spearman's correlation coefficient was used as a measure of the strength of association between two variables. For all the mentioned statistical tests, $P$ values of $>0.05$ indicated non-significant results, while $P$ values of $<0.05$ indicated significant results.

\section{Results}

\section{Death and post-operative infection rates}

Out of the initial 65 rats allocated for this study, 14 rats were eliminated due to either death or infections. A total of 10 rats died following the stereotaxic procedure, constituting a death rate of $15.38 \%$ (3 in the STZ group, 3 in the STZ-Letrozole group, 2 in the CSF group and 2 in the CSF-LV group). All rats died within the first 24 hours following the stereotaxic injection. Four rats developed a localized infection, constituting an infection rate of $6.15 \%$ (2 in the CSF group and 2 in the CSF-LV group). The infection was either in the head wounds following the stereotaxic injection or in the abdomen at the site of the anesthesia injection. The remaining 51 rats were involved in the remainder experiments and subsequently the statistical analysis.

\section{Verification of neurodegeneration in the STZ-injected rats via histological examination}

Histological examination of H\&E stained hippocampal sections from STZ-injected rats showed signs of degeneration as well as inflammatory changes (Fig. 1).

Comparing the state of working memory (in alternation percentage) and p-Tau levels among the different studied groups

Tables (1, 2 and 3$)$ show that there were statistically significant differences between different groups in both alternation percentage and $\mathrm{p}$-Tau concentration.

Comparing Let-7 miRNAs expression (in fold change) among the studied groups 
Tables (4, 5, 6 and 7$)$ and figures $(2,3$ and 4$)$ show that there were statistically significant differences between the different groups in the expression of Let-7 a, b \& e. Using LSD to compare each two groups, it was found that there were no statistically significant differences between the Intact, CSF, LV, CSF-LV and STZ groups in the expression of any of the studied miRNAs.

However, there was a statistically significant elevation in the expression levels of all studied miRNAs in the Letrozole group compared with the Intact, CSF, LV, CSF-LV and STZ groups. There was also a statistically significant elevation in the expression levels of all studied miRNAs in the STZ-L group compared with the Intact, CSF, LV, CSF-LV and STZ groups. Finally no difference was found between Letrozole group and STZ-L group in the expression level of any of the studied miRNAs.

\section{Correlation between memory status (in alternation percentage), p-Tau concentration and Let-7 miRNAs expression (in fold change) among different studied groups}

Table (8) and figures $(5,6$ and 7$)$ show that there were statistically significant negative correlations between alternation percentage and the expression levels of Let-7a $(P=0.01)$, Let-7b $(P=0.002)$ \& Let-7e $(P<0.001)$ and $p$-Tau concentration $(P<0.001)$. Also, there were statistically significant positive correlation between $p$-Tau concentration and the expression levels of Let-7a $(P<0.001)$, Let-7b $(P<0.001)$ \& Let-7e $(P<0.001)$.

\section{Discussion}

AD causes aging-related cognitive impairment and dementia (Davey, 2017). Amnesic presentations as well as the presence of $A \beta$ plaques and neurofibrillary tangles of filamentous Tau proteins are required for diagnosis (Perl, 2010 and DeTure and Dickson, 2019). Studies have shown that the cerebral glucose mobilization disorders are either preceding or accompanying the initial cognitive impairments in sporadic AD (De La Monte and Wands, 2005; Rivera et al., 2005).

Multiple studies provide evidence of the possible involvement of microRNA (miRNA) Let-7 family members in $A D$, and their neurotoxicity. These studies include models of $A \beta_{40}$-incduced neurotoxicity in cell lines (Gu et al., 2017), injection of Let-7b into the CSF of wild-type mice (Lehmann et al., 2012), quantification of Let-7 miRNAs in the CSF of AD patients (Derkow et al., 2018), miRNA profiling of the brains of transgenic AD mice (Wang et al., 2009 and Wang et al., 2017), and studying the expression of miRNAs in the brains of a cholesterol-based rabbit model of AD (Liu et al., 2014).

Prior to this current study, levels of Let-7 miRNAs were not investigated in an STZ-induced SAD model, neither was the effect of Let-7 modulation on the memory of the animals in such model.

Multiple drugs were found to increase the expression of Let-7 in various cell lines (Lozier et al., 2015; Francess et al., 2018), an example of which is Letrozole (Shibahara et al., 2012; Cho et al., 2016), which is a potent aromatase inhibitor that can cross the BBB (Dave et al., 2013). Controversial data exist regarding 
the effects of aromatase inhibitors (Als), including Letrozole, on memory in rodents (Alejandre-Gomez et al., 2007; Aydin et al., 2008; Nayebi et al., 2014 and Zameer and Vohora, 2017).

Results of the present work showed that STZ, Letrozole and STZ+Letrozole administration all caused memory impairments in rats, as evident by decreases in the alternation percentages of these groups compared to the control groups. The degree of memory impairment was more severe in the STZ+Letrozole rats, followed by the STZ group, then by the Letrozole group that showed the least degree of memory impairment.

These results are partially in agreement with Nayebi et al., (2014), whose results also showed a significant memory impairment in the STZ, Letrozole, STZ+Letrozole groups compared to the controls. However, while their results indicated that the Letrozole group had the least severe impairment among the three groups, there was no significant difference in the degree of memory impairment in the STZ group compared to the STZ+Letrozole group.

This discrepancy between our and their sets of results may arise from: 1) Differences in the animal strains used, as they used Wistar rats, 2) The dose of Letrozole given and the route of administration, as they used a $6 \mathrm{mg} / \mathrm{kg}$ dose administrated intraperitoneally, or 3) The use of a different memory test; the passive avoidance test. Passive avoidance and T-maze tests were shown to give different results while testing the effects of other drugs on memory processes (Wang et al., 2006).

Regarding the level of p-Tau (Ser396), results of our study showed a significant increase of $p$-Tau in the STZ, Letrozole and STZ+Letrozole groups compared to the control groups. While the administration of ICV-STZ leading to generation of hyperphosphorylated Tau and Tau pathology similar to that of AD was extensively documented in literature and previous studies (Grünblatt et al., 2007; Qu et al., 2011; Lee et al., 2013; Peng et al., 2013; Shi et al., 2017; Gupta et al., 2018; Mishra et al., 2018), the possible effect of Letrozole on hyperphosphorylated Tau levels is underexplored.

Hippocampal levels of $\mathrm{p}$-Tau showed a significant negative correlation with the alternation percentages in the current study, which was postulated; as there is an evidence showing that both plasma and CSF levels of Tau correlate with the incidence of AD dementia in patients (Pase et al., 2019), and that CSF Tau levels have an inverse correlation with the short-term memory scores in patients with AD (Lin et al., 2009).

Regarding the expression levels of Let-7 $a, b$ and e, miRNAs, we are first to report the expression patterns of these three miRNAs in an STZ-induced SAD rat model. Let-7a, $b$ and e miRNAs were not differentially expressed in the STZ group compared to the controls, as there was no significant differences in fold change of any of the three miRNAs between the STZ group and the controls.

Multiple studies have examined the expression levels of various Let-7 miRNAs in different models, samples and time intervals. For example, studies examining Let-7 members in the CSF of AD patients - of different subtypes- have found Let-7a-3p, b, e, f and i to be upregulated (Cogswell et al., 2008; Sørensen 
et al., 2016; Derkow et al., 2018 and Lv et al., 2018), while Let-7a was found to be downregulated in the CSF of patients with late onset AD (Van Harten et al., 2015).

Studies examining Let-7 members in either the serum or plasma of $A D$ and $\mathrm{MCl}$ patients have found Let$7 f$ to be upregulated in AD (Hara et al., 2017), and Let-7b to be upregulated in $\mathrm{MCl}$ (Kenny et al., 2019), while Let-7d, g and i were downregulated (Kumar et al., 2013; Tan et al., 2014; Gámez-Valero et al., 2019).

Animal studies on different transgenic AD mice and cholesterol-induced AD rabbits have found Let-7a, $b$, $c, d, e$ and $f$ to be upregulated in the brain at different time intervals (Wang et al., 2009; Liu et al., 2014 and Wang et al., 2017).

It is obvious that changes in the model, the sample, type of AD, Let-7 tested, and the age of the subject at which the samples were obtained yielded different results. Thus, it was not unexpected that the model chosen for the current study might show different results, since none of the previous studies, to date, have examined the levels of Let-7 in a similar STZ-induced AD rodent model. It may also be assumed that measuring expression levels of Let-7 in aged STZ-induced AD rats might yield different results than the ones obtained from this current study, as we only examined the hippocampal levels of selected Let-7 miRNAs after three weeks of STZ injection, i.e. during the acute impairment stage of this model.

Non-significant differences in the expression of Let-7 a, b and e in the STZ group does not necessarily mean that these miRNAs are not implicated in the disease process in this model. Let-7 activity was shown to be regulated by another miRNA, miR-107. miR-107 directly interacts with Let-7, suppresses its function and promotes its degradation (Chen et al., 2011). miR-107 was found to be downregulated in AD in multiple studies (Wang et al., 2008; Shamsuzzama et al., 2016; Herrera-Espejo et al., 2019; Swarbrick et al., 2019). It was also found to be deregulated in STZ-induced diabetic animals (Balbaa et al., 2017). Decreases in miR-107 levels or activity can lead to Let-7 stabilization and preservation of its action on the target genes (Jiang, 2019). However, further research is needed to elucidate the relation between Let-7 and miR-107 in AD.

On the other hand, Letrozole was successfully associated with Let-7a, b and e upregulation in the Letrozole and the STZ+Letrozole groups, which showed significant differences in Let-7a, b and e expression levels compared to all other groups. No significant difference was found in the expression of Let-7a, b or e between the Letrozole group and the STZ+Letrozole group, further serving to relate the observed upregulation to the action of Letrozole.

The observed effect of Letrozole on Let-7 miRNAs was not unexpected, as Letrozole was shown to be able to cross the BBB (Kil et al., 2009 and Dave et al., 2013), and it was previously shown to be associated with increased expression of various Let-7 miRNAs, including Let-7f, b and $a$, in various cancer models (Shibahara et al., 2012; Cho et al., 2016; Isanejad et al., 2016).

Analysis of the current data showed significant correlations between Let-7a, $b$ and e levels and both the alternation percentage and $\mathrm{p}$-Tau level in the hippocampus. There was a significant negative correlation 
between the expression level of each of the Let-7 miRNAs tested (Let-7a, b and e) and the alternation percentage, and a significant positive correlation between the expression level of each of the Let-7 miRNAs tested and the hippocampal p-Tau level.

Studies exploring possible correlations between Let-7 members and either or both cognitive impairment and p-Tau levels are scarce, and majorly differ from the current work in regards to the type of sample, and the type of cognitive test/exam which is determined by the species to be examined.

For instance, Kenny et al., (2019) found no significant correlation between Let-7b expression and the cognitive decline in $\mathrm{MCl}$ patients, and Derkow et al., (2018) did not observe a significant correlation between amounts of $A \beta_{42}$ or total-Tau and Let-7b or Let-7e expression in the CSF of $A D$ patients. Further research is needed to establish more evidence in regards to Let-7 correlation with memory status and $p$ Tau levels, preferably using larger samples and different AD models.

Based on the findings of this current study, Letrozole alone was sufficient to show a significant degree of memory impairment, but, the more severe impairment in the STZ+Letrozole group could further support the idea of a synergistic effect exerted by Letrozole in presence of an additional insult (Chang et al., 2013).

This current study cannot confirm whether this effect is due to the additional neurosteroidal deficit caused by Letrozole or its modulation of some neurotoxic miRNAs of the Let-7 family.

Upregulated Let-7 could play a role in the pathogenesis of AD by affecting multiple pathways that relate to insulin signaling and neuroinflammation, and are known to be disturbed by STZ administration as well as being regulated by estrogen.

STZ can accumulate via GLUT2 transporter uptake (Eleazu et al., 2013), and mRNA expression of insulin receptors (IR), and insulin-like growth factor-1 receptors (IGF-1R) and their protein levels in the membrane of hippocampal cells decrease after STZ administration (Salkovic-Petrisic and Hoyer, 2007). Insulin receptor substrates (IRSs) and Akt phosphorylation (i.e. activation) also decrease, resulting in disruption of the insulin signaling pathway, which was implicated in the process of learning and memory (Agrawal et al., 2011). An impairment of the insulin signaling pathway leads to activation of GSK3, ultimately resulting in hyperphosphorylation of Tau protein (Mishra et al., 2018) and promoting $A \beta$ accumulation (Kamat et al., 2016). STZ also upregulates BACE1, which can result in increased cleavage of APP (Mishra et al., 2018).

Let-7 was found to target the mRNAs of the insulin signaling pathway players, such as IR, IGF1R, IRS, PI3K and Akt (Frost and Olson, 2011; Zhu et al., 2011) and Let-7 transfection into a human cell line led to reduction IR and IRS (Zhu et al., 2011).

We suggest that it is possible that the upregulation of Let-7 in the hippocampus could aggravate the toxic effects of STZ via further dysregulation and inhibition of the insulin signaling pathway. This suggestion can be supported by a recent study that found that LIN-28a, which is a powerful inhibitor of Let-7 
biogenesis, prevented the toxic effects of STZ on pancreatic $\beta$ - cells, and that LIN-28a downregulation of Let-7 was associated with increased phosphorylation of PI3K and Akt in a mouse insulinoma cell line (Sung et al., 2019).

Interestingly, estrogen binding to G-coupled estrogen receptor (GPER) could result in the activation of the PI3K/Akt pathway (Peixoto et al., 2017; Bian et al., 2019), which could lead to memory enhancement (Frick, 2019). In addition, the estrogen/ER-PI3K-Akt pathway has been shown to be a neuroprotective factor against toxic insults for neuronal cells (Honda et al., 2000). It might be possible that the estrogenreducing effect of Letrozole could have also added to the inhibition of the PI3K-Akt pathway already caused by the STZ toxicity and the upregulation of Let-7.

Another pathway by which upregulation of Let-7 could aggravate the effect of an STZ-induced lesion is through increasing neuroinflammation. STZ leads to increased expression of neuroinflammation markers such as NF-KB (Nuclear factor kappa light chain enhancer of activated B cells), and Glial fibrillary acidic protein (GFAP) positive astrocytes in the hippocampus (Islam et al., 2015; Mishra et al., 2018). Increased expression and activation of astrocytes for prolonged periods of time is evident in AD brain, in which severity of glial activation correlated with cognitive decline (Parachikova et al., 2007). Activation of astrocyte is accompanied by increased production of potentially neurotoxic factors including inflammatory cytokines, nitric oxide and reactive oxygen species (Zameer et al., 2019).

Microglia express Toll-like receptors (TLRs), which play an important role in the immune response as they recognize pathogen molecules. TLRs activation leads to subsequent activation of intracellular signaling cascades that ultimately cause the release of inflammatory molecules (Lehmann et al., 2012; Buonfiglioli et al., 2019). Let-7 is a potent activator of TLR7 signaling in microglia and neurons, leading to induction of NF-KB in microglia, an inflammatory response and initiation of neurodegeneration (Lehmann et al., 2012), which can add to the already existing pro-inflammatory effects of STZ, aggravating its neurodegenerative actions.

\section{Declarations}

Funding: The authors received no financial support for the research, authorship, and/or publication of this article.

Conflicts of interest/Competing interests: The authors declare that there is no conflict of interest.

Availability of data and material (data transparency): Data supporting the findings of this study are available from the corresponding author upon reasonable request.

Code availability (software application or custom code): Not applicable.

Ethics approval: An ethical approval for this study was obtained from the Institutional Animal Care and Use Committee (IACUC), Zagazig University, in line with the Guide for the Care and Use of Laboratory Animals 8th Edition 2011. 
Consent to participate: Not applicable.

Consent for publication: Not applicable.

\section{References}

Agrawal, R. et al. (2011) 'Insulin receptor signaling in rat hippocampus: A study in STZ (ICV) induced memory deficit model', European Neuropsychopharmacology, 21(3), pp. 261-273. doi:

10.1016/j.euroneuro.2010.11.009.

Alejandre-Gomez, M., Garcia-Segura, L. M. and Gonzalez-Burgos, I. (2007) 'Administration of an inhibitor of estrogen biosynthesis facilitates working memory acquisition in male rats.', Neuroscience research, 58(3), pp. 272-277. doi: 10.1016/j.neures.2007.03.011.

Aydin, M. et al. (2008) 'Effects of letrozole on hippocampal and cortical catecholaminergic neurotransmitter levels, neural cell adhesion molecule expression and spatial learning and memory in female rats.', Neuroscience, 151(1), pp. 186-194. doi: 10.1016/j.neuroscience.2007.09.005.

Bakker, R., Tiesinga, P. and Kötter, R. (2015) 'The Scalable Brain Atlas: Instant Web-Based Access to Public Brain Atlases and Related Content', Neuroinformatics. Humana Press Inc., 13(3), pp. 353-366. doi: 10.1007/s12021-014-9258-x.

Balbaa, M., Abdulmalek, S. A. and Khalil, S. (2017) 'Oxidative stress and expression of insulin signaling proteins in the brain of diabetic rats: Role of Nigella sativa oil and antidiabetic drugs', PLOS ONE. Public Library of Science, 12(5). doi: 10.1371/journal.pone.0172429.

Bian, C. et al. (2019) '17 $\beta$-Estradiol Regulates Glucose Metabolism and Insulin Secretion in Rat Islet $\beta$ Cells Through GPER and Akt/mTOR/GLUT2 Pathway', Frontiers in Endocrinology, 10, p. 531. doi: 10.3389/fendo.2019.00531.

Buonfiglioli, A. et al. (2019) 'let-7 MicroRNAs Regulate Microglial Function and Suppress Glioma Growth through Toll-Like Receptor 7', Cell Reports. Elsevier B.V., 29(11), pp. 3460-3471.e7. doi: 10.1016/j.celrep.2019.11.029.

Chang, P. K.-Y. et al. (2013) 'Letrozole Potentiates Mitochondrial and Dendritic Spine Impairments Induced by $\beta$ Amyloid.', Journal of aging research, 2013, p. 538979. doi: 10.1155/2013/538979.

Chen, P. S. et al. (2011) 'miR-107 promotes tumor progression by targeting the let-7 microRNA in mice and humans', Journal of Clinical Investigation, 121(9), pp. 3442-3455. doi: 10.1172/JCl45390.

Cho, S. et al. (2016) 'Aromatase inhibitor regulates let-7 expression and let-7f-induced cell migration in endometrial cells from women with endometriosis.', Fertility and sterility. NIH Public Access, 106(3), pp. 673-80. 
Cogswell, J. et al. (2008) 'Identification of miRNA Changes in Alzheimer's.pdf', Journal of Alzheimer's Disease, 14, pp. 27-41.

Cold spring harbor (2011) 'Artificial cerebrospinal fluid (ACSF)', Cold Spring Harbor Protocols. Cold Spring Harbor Laboratory, 2011(9). doi: 10.1101/pdb.rec065730.

Dave, N., Gudelsky, G. A. and Desai, P. B. (2013) 'The pharmacokinetics of letrozole in brain and brain tumor in rats with orthotopically implanted C6 glioma, assessed using intracerebral microdialysis.', Cancer chemotherapy and pharmacology, 72(2), pp. 349-357. doi: 10.1007/s00280-013-2205-y.

Davey, D. A. (2017) 'Prevention of Alzheimer's disease, cerebrovascular disease and dementia in women: the case for menopause hormone therapy', Neurodegenerative disease management, 7(1), pp. 85-94. doi: 10.2217/nmt-2016-0044.

Deacon, R. M. J. J. and Rawlins, J. N. P. (2006) 'T-maze alternation in the rodent', Nature Protocols, 1(1), pp. 7-12. doi: 10.1038/nprot.2006.2.

Derkow, K. et al. (2018) 'Distinct expression of the neurotoxic microRNA family let-7 in the cerebrospinal fluid of patients with Alzheimer's disease', PLOS ONE. Public Library of Science, 13(7), pp. 1-18. doi: 10.1371/journal.pone.0200602.

Desjardins, P. and Conklin, D. (2010) 'NanoDrop microvolume quantitation of nucleic acids', Journal of Visualized Experiments. Journal of Visualized Experiments, (45), p. 2565. doi: 10.3791/2565.

DeTure, M. A. and Dickson, D. W. (2019) 'The neuropathological diagnosis of Alzheimer's disease', Molecular Neurodegeneration, 14(1), p. 32. doi: 10.1186/s13024-019-0333-5.

Eleazu, C. O. et al. (2013) 'Review of the mechanism of cell death resulting from streptozotocin challenge in experimental animals, its practical use and potential risk to humans', Journal of Diabetes and Metabolic Disorders. BioMed Central Ltd., 12(1), p. 60. doi: 10.1186/2251-6581-12-60.

Francess, E. M. et al. (2018) 'Modulation of LIN28B/let-7 signaling by propranolol contributes to infantile hemangioma involution', Arteriosclerosis, Thrombosis, and Vascular Biology. Lippincott Williams and Wilkins, 38(6), pp. 1321-1332. doi: 10.1161/ATVBAHA.118.310908.

Frick, K. M. (2019) Estrogens and Memory: Basic Research and Clinical Implications. Oxford University Press (Oxford Series in Behavioral Neuroendocrinology).

Frost, R. J. A. and Olson, E. N. (2011) 'Control of glucose homeostasis and insulin sensitivity by the Let-7 family of microRNAs', Proceedings of the National Academy of Sciences of the United States of America, 108(52), pp. 21075-21080. doi: 10.1073/pnas.1118922109.

Gámez-Valero, A. et al. (2019) 'Exploratory study on microRNA profiles from plasma-derived extracellular vesicles in Alzheimer's disease and dementia with Lewy bodies', Translational Neurodegeneration. 
BioMed Central Ltd., 8(1), p. 31. doi: 10.1186/s40035-019-0169-5.

Grünblatt, E. et al. (2007) 'Brain insulin system dysfunction in streptozotocin intracerebroventricularly treated rats generates hyperphosphorylated tau protein', Journal of Neurochemistry, 101(3), pp. 757-770. doi: 10.1111/j.1471-4159.2006.04368.x.

Gu, H. et al. (2017) 'Overexpression of let-7a increases neurotoxicity in a PC12 cell model of Alzheimer's disease via regulating autophagy.', Experimental and therapeutic medicine. Spandidos Publications, 14(4), pp. 3688-3698. doi: 10.3892/etm.2017.4977.

Gupta, S. et al. (2018) 'Evidence for Compromised Insulin Signaling and Neuronal Vulnerability in Experimental Model of Sporadic Alzheimer's Disease', Molecular Neurobiology. Humana Press Inc., 55(12), pp. 8916-8935. doi: 10.1007/s12035-018-0985-0.

Hara, N. et al. (2017) 'Serum microRNA miR-501-3p as a potential biomarker related to the progression of Alzheimer's disease', Acta Neuropathologica Communications, 5(1), p. 10. doi: 10.1186/s40478-017-0414Z.

Van Harten, A. C. et al. (2015) 'Differential Expression of microRNA in Cerebrospinal Fluid as a Potential Novel Biomarker for Alzheimer's Disease', Journal of Alzheimer's Disease. IOS Press, 47(1), pp. 243-252. doi: 10.3233/JAD-140075.

Hau, J. and Schapiro, S. J. (2002) Handbook of Laboratory Animal Science: Essential Principles and Practices. 2nd edn. CRC Press.

Herrera-Espejo, S. et al. (2019) 'A Systematic Review of MicroRNA Expression as Biomarker of Late-Onset Alzheimer's Disease', Molecular Neurobiology. Humana Press Inc., 56(12), pp. 8376-8391. doi: 10.1007/s12035-019-01676-9.

Honda, K. et al. (2000) 'Phosphatidylinositol 3-kinase mediates neuroprotection by estrogen in cultured cortical neurons', Journal of Neuroscience Research, 60(3), pp. 321-327. doi: 10.1002/(SICI)10974547(20000501)60:3<321::AID-JNR6>3.0.C0;2-T.

Isanejad, A. et al. (2016) 'MicroRNA-206, Let-7 and microRNA-21 pathways involved in the antiangiogenesis effects of the interval exercise training and hormone therapy in breast cancer', Life Sciences. Elsevier B.V., 151, pp. 30-40. doi: 10.1016/j.Ifs.2016.02.090.

Islam, Fakhrul et al. (2015) 'Effect of hesperidin on neurobehavioral, neuroinflammation, oxidative stress and lipid alteration in intracerebroventricular streptozotocin induced cognitive impairment in mice', Journal of the Neurological Sciences. Elsevier, 348(1-2), pp. 51-59. doi: 10.1016/j.jns.2014.10.044.

Jiang, S. (2019) 'A Regulator of Metabolic Reprogramming: MicroRNA Let-7', Translational Oncology. Neoplasia Press, Inc., 12(7), pp. 1005-1013. doi: 10.1016/j.tranon.2019.04.013. 
Kamat, P. K. et al. (2016) 'Streptozotocin Intracerebroventricular-Induced Neurotoxicity and Brain Insulin Resistance: a Therapeutic Intervention for Treatment of Sporadic Alzheimer's Disease (SAD)-Like Pathology', Molecular Neurobiology. Humana Press Inc., 53(7), pp. 4548-4562. doi: 10.1007/s12035-0159384-y.

Kenny, A. et al. (2019) 'Elevated Plasma microRNA-206 Levels Predict Cognitive Decline and Progression to Dementia from Mild Cognitive Impairment', Biomolecules, 9(11), p. 734. doi: 10.3390/biom9110734.

Kil, K. E. et al. (2009) 'Synthesis and PET studies of [11C-cyano]letrozole (Femara), an aromatase inhibitor drug', Nuclear Medicine and Biology, 36(2), pp. 215-223. doi: 10.1016/j.nucmedbio.2008.11.010.

Kjonigsen, L. J. et al. (2015) 'Waxholm Space atlas of the rat brain hippocampal region: Threedimensional delineations based on magnetic resonance and diffusion tensor imaging', Neurolmage. Academic Press Inc., 108, pp. 441-449. doi: 10.1016/j.neuroimage.2014.12.080.

Kumar, P. et al. (2013) 'Circulating miRNA Biomarkers for Alzheimer's Disease', PLoS ONE, 8(7). doi: 10.1371/journal.pone.0069807.

De La Monte, S. M. and Wands, J. R. (2005) 'Review of insulin and insulin-like growth factor expression, signaling, and malfunction in the central nervous system: Relevance to Alzheimer's disease', Journal of Alzheimer's Disease. IOS Press, 7(1), pp. 45-61. doi: 10.3233/JAD-2005-7106.

Lane, C. A., Hardy, J. and Schott, J. M. (2018) 'Alzheimer's disease', European Journal of Neurology. John Wiley \& Sons, Ltd (10.1111), 25(1), pp. 59-70. doi: 10.1111/ene.13439.

Langhans, W. et al. (2016) 'Routine animal use procedures', University of Zurich, Institute of Laboratory Animal Science, (June), pp. 1-34.

Lee, C.-W. et al. (2013) 'Hypoglycemia Induces Tau Hyperphosphorylation', Current Alzheimer Research. Bentham Science Publishers Ltd., 10(3), pp. 298-308. doi: 10.2174/1567205011310030009.

Lee, H. et al. (2016) 'Biogenesis and regulation of the let-7 miRNAs and their functional implications.', Protein \& cell. Springer, 7(2), pp. 100-13. doi: 10.1007/s13238-015-0212-y.

Lehmann, S. M. et al. (2012) 'An unconventional role for miRNA: let-7 activates Toll-like receptor 7 and causes neurodegeneration.', Nature neuroscience, 15(6), pp. 827-35. doi: 10.1038/nn.3113.

Lin, Y. Te et al. (2009) 'Increased total TAU but not amyloid- $\beta 42$; In cerebrospinal fluid correlates with short-term memory impairment in Alzheimer's disease', Journal of Alzheimer's Disease. IOS Press, 18(4), pp. 907-918. doi: 10.3233/JAD-2009-1214.

Liu, Q. Y. et al. (2014) 'Identification of microRNAs involved in Alzheimer's progression using a rabbit model of the disease.', American journal of neurodegenerative disease, 3(1), pp. 33-44. 
Livak, K. J. and Schmittgen, T. D. (2001) 'Analysis of relative gene expression data using real-time quantitative PCR and the 2- $\Delta \Delta C$ CT method', Methods. Academic Press Inc., 25(4), pp. 402-408. doi: 10.1006/meth.2001.1262.

Lozier, A. M. et al. (2015) 'Targeting ornithine decarboxylase reverses the LIN28/Let-7 axis and inhibits glycolytic metabolism in neuroblastoma', Oncotarget. Impact Journals LLC, 6(1), pp. 196-206. doi: 10.18632/oncotarget.2768.

Lv, Z. et al. (2018) 'Comparative study of microRNA profiling in one Chinese Family with PSEN1 G378E mutation', Metabolic Brain Disease. Springer New York LLC, 33(5), pp. 1711-1720. doi: 10.1007/s11011018-0279-2.

Mehla, J., Pahuja, M. and Gupta, Y. K. (2013) 'Streptozotocin-Induced Sporadic Alzheimer' s Disease: Selection of Appropriate Dose', Journal of Alzheimer's disease: JAD, 33(1), pp. 17-21. doi: 10.3233/JAD2012-120958.

Mishra, S. K. et al. (2018) 'Intracerebroventricular streptozotocin impairs adult neurogenesis and cognitive functions via regulating neuroinflammation and insulin signaling in adult rats', Neurochemistry International. Elsevier Ltd, 113, pp. 56-68. doi: 10.1016/j.neuint.2017.11.012.

Nayebi, A. M., Pourrabi, S. and Hossini, S. (2014) 'Testosterone ameliorates streptozotocin-induced memory impairment in male rats', Acta Pharmacologica Sinica, 35(6), pp. 752-757. doi: 10.1038/aps.2014.6.

Papp, E. A. et al. (2014) 'Waxholm Space atlas of the Sprague Dawley rat brain', Neurolmage. Academic Press Inc., 97, pp. 374-386. doi: 10.1016/j.neuroimage.2014.04.001.

Parachikova, A. et al. (2007) 'Inflammatory changes parallel the early stages of Alzheimer disease', Neurobiology of Aging, 28(12), pp. 1821-1833. doi: 10.1016/j.neurobiolaging.2006.08.014.

Pase, M. P. et al. (2019) 'Assessment of Plasma Total Tau Level as a Predictive Biomarker for Dementia and Related Endophenotypes', JAMA Neurology. American Medical Association, 76(5), pp. 598-606. doi: 10.1001/jamaneurol.2018.4666.

Paxinos, G. and Watson, C. (2006) The rat brain in stereotaxic coordinates: hard cover edition. Elsevier.

Peixoto, P. et al. (2017) 'GPER agonist dilates mesenteric arteries via PI3K-Akt-eNOS and potassium channels in both sexes', Life Sciences. Elsevier Inc., 183, pp. 21-27. doi: 10.1016/j.Ifs.2017.06.020.

Peng, D. et al. (2013) 'Hyperphosphorylation of tau protein in hippocampus of central insulin-resistant rats is associated with cognitive impairment', Cellular Physiology and Biochemistry, 32(5), pp. 1417-1425. doi: $10.1159 / 000356579$. 
Perl, D. P. (2010) 'Neuropathology of Alzheimer's disease', Mount Sinai Journal of Medicine, 77(1), pp. 3242. doi: $10.1002 / \mathrm{msj} .20157$.

Qu, Z. et al. (2011) 'Effects of streptozotocin-induced diabetes on tau phosphorylation in the rat brain', Brain Research, 1383, pp. 300-306. doi: 10.1016/j.brainres.2011.01.084.

Rivera, E. J. et al. (2005) 'Insulin and insulin-like growth factor expression and function deteriorate with progression of Alzheimer's disease: Link to brain reductions in acetylcholine', Journal of Alzheimer's Disease. IOS Press, 8(3), pp. 247-268. doi: 10.3233/JAD-2005-8304.

Salkovic-Petrisic, M. and Hoyer, S. (2007) 'Central insulin resistance as a trigger for sporadic Alzheimerlike pathology: an experimental approach', in Neuropsychiatric Disorders An Integrative Approach. Springer Vienna, pp. 217-233. doi: 10.1007/978-3-211-73574-9_28.

Schmittgen, T. D. and Livak, K. J. (2008) 'Analyzing real-time PCR data by the comparative CT method', Nature Protocols, 3(6), pp. 1101-1108. doi: 10.1038/nprot.2008.73.

Sergejeva, M. et al. (2015) 'Anatomical landmarks for registration of experimental image data to volumetric rodent brain atlasing templates', Journal of Neuroscience Methods. Elsevier, 240, pp. 161-169. doi: 10.1016/j.jneumeth.2014.11.005.

Shamsuzzama et al. (2016) 'Role of MicroRNA Let-7 in Modulating Multifactorial Aspect of Neurodegenerative Diseases: an Overview', Molecular Neurobiology, 53(5), pp. 2787-2793. doi: 10.1007/s12035-015-9145-y.

Shi, L. et al. (2017) 'A novel dual GLP-1/GIP receptor agonist alleviates cognitive decline by re-sensitizing insulin signaling in the Alzheimer icv. STZ rat model', Behavioural Brain Research. Elsevier B.V., 327, pp. 65-74. doi: 10.1016/j.bbr.2017.03.032.

Shibahara, Y. et al. (2012) 'Aromatase inhibitor treatment of breast cancer cells increases the expression of let-7f , a microRNA targeting CYP19A1', The Journal of Pathology, 227(April), pp. 357-366. doi: 10.1002/path.4019.

Silva, R. H. et al. (2004) 'Role of hippocampal oxidative stress in memory deficits induced by sleep deprivation in mice', Neuropharmacology, 46(6), pp. 895-903. doi: 10.1016/j.neuropharm.2003.11.032.

Sørensen, S. S., Nygaard, A. B. and Christensen, T. (2016) 'miRNA expression profiles in cerebrospinal fluid and blood of patients with Alzheimer's disease and other types of dementia - an exploratory study', Translational Neurodegeneration. BioMed Central Ltd., 5(1). doi: 10.1186/s40035-016-0053-5.

Spijker, S. (2011) 'Dissection of rodent brain regions', Neuromethods, 57, pp. 13-26. doi: 10.1007/978-161779-111-6_2. 
Sung, Y. et al. (2019) 'Lin28a expression protects against streptozotocin-induced $\beta$-cell destruction and prevents diabetes in mice', Cell Biochemistry and Function. John Wiley and Sons Ltd, 37(3), pp. 139-147. doi: $10.1002 /$ cbf.3376.

Swarbrick, S. et al. (2019) 'Systematic Review of miRNA as Biomarkers in Alzheimer's Disease', Molecular Neurobiology. Humana Press Inc., 56(9), pp. 6156-6167. doi: 10.1007/s12035-019-1500-y.

Tan, Lin et al. (2014) 'Genome-wide serum microRNA expression profiling identifies serum biomarkers for Alzheimer's disease', Journal of Alzheimer's Disease. IOS Press, 40(4), pp. 1017-1027. doi: 10.3233/JAD132144.

The University of Texas at Austin (2013) 'Guidelines for the Use of Cervical Dislocation for Rodent Euthanasia The University of Texas at Austin Institutional Animal Care and Use Committee', pp. 1-2.

Wang, J. H. et al. (2006) 'Ketamine affects memory consolidation: Differential effects in T-maze and passive avoidance paradigms in mice', Neuroscience, 140(3), pp. 993-1002. doi:

10.1016/j.neuroscience.2006.02.062.

Wang, L. et al. (2017) 'Profiling microRNA from Brain by Microarray in a Transgenic Mouse Model of Alzheimer's Disease', 2017.

Wang, L. L. et al. (2017) 'Profiling microRNA from Brain by Microarray in a Transgenic Mouse Model of Alzheimer's Disease', BioMed Research International. Hindawi Limited, 2017, p. 8030369. doi:

$10.1155 / 2017 / 8030369$.

Wang, W. X. et al. (2008) 'The expression of microRNA miR-107 decreases early in Alzheimer's disease and may accelerate disease progression through regulation of $\beta$-site amyloid precursor protein-cleaving enzyme 1', Journal of Neuroscience, 28(5), pp. 1213-1223. doi: 10.1523/JNEUROSCI.5065-07.2008.

Wang, X. et al. (2009) 'miR-34a, a microRNA up-regulated in a double transgenic mouse model of Alzheimer's disease, inhibits bcl2 translation', Brain Research Bulletin, 80(4-5), pp. 268-273. doi: 10.1016/j.brainresbull.2009.08.006.

Wu, C. Y. C. et al. (2018) 'Utilizing the modified T-maze to assess functional memory outcomes after cardiac arrest', Journal of Visualized Experiments. Journal of Visualized Experiments, 2018(131). doi: $10.3791 / 56694$.

Zameer, S. et al. (2019) 'Ameliorative effect of alendronate against intracerebroventricular streptozotocin induced alteration in neurobehavioral, neuroinflammation and biochemical parameters with emphasis on A $\beta$ and BACE-1', NeuroToxicology. Elsevier B.V., 70, pp. 122-134. doi: 10.1016/j.neuro.2018.11.012.

Zameer, S. and Vohora, D. (2017) 'Effect of aromatase inhibitors on learning and memory and modulation of hippocampal dickkopf-1 and sclerostin in female mice', Pharmacological Reports, 69(6), pp. 13001307. doi: 10.1016/j.pharep.2017.06.002. 
Zhu, H. et al. (2011) 'The Lin28/let-7 axis regulates glucose metabolism.', Cell. NIH Public Access, 147(1), pp. 81-94. doi: 10.1016/j.cell.2011.08.033.

\section{Tables}

Table (1): Alternation percentage and p-Tau concentration among the studied groups

\begin{tabular}{|c|c|c|}
\hline $\begin{array}{l}\text { Parameter } \\
\text { Groups }\end{array}$ & $\begin{array}{c}\text { Memory status } \\
\text { (Alternation percentage) } \\
\text { Mean } \pm \text { SD } \\
\text { Range }\end{array}$ & $\begin{array}{c}\text { p-Tau concentration } \\
(\mathrm{pg} / \mathrm{ml}) \\
\text { Mean } \pm \mathrm{SD} \\
\text { Range }\end{array}$ \\
\hline Intact $(n=6)$ & $\begin{array}{c}76.67 \pm 12.12^{\mathrm{a}} \\
60-90\end{array}$ & $\begin{array}{c}16.87 \pm 2.7^{\mathrm{a}} \\
13.6-19.32\end{array}$ \\
\hline $\operatorname{CSF}(n=6)$ & $\begin{array}{c}81.67 \pm 14.72^{a} \\
60-100\end{array}$ & $\begin{array}{c}18.29 \pm 2.77^{a} \\
14.78-21.14\end{array}$ \\
\hline LV $(n=6)$ & $\begin{array}{c}73.33 \pm 8.16^{a} \\
60-80\end{array}$ & $\begin{array}{c}17.70 \pm 2.05^{\mathrm{a}} \\
13.74-19.2^{-}\end{array}$ \\
\hline CSF-LV $(n=6)$ & $\begin{array}{c}78.33 \pm 11.69^{a} \\
60-90\end{array}$ & $\begin{array}{c}18.89 \pm 0.80^{\mathrm{a}} \\
18-20.05\end{array}$ \\
\hline STZ $(n=9)$ & $\begin{array}{c}35.56 \pm 8.82^{b} \\
20-50\end{array}$ & $\begin{array}{l}22.36 \pm 0.83^{b} \\
21.14-23.61\end{array}$ \\
\hline Letrozole $(n=9)$ & $\begin{array}{c}53.33 \pm 8.66^{\mathrm{c}} \\
40-60\end{array}$ & $\begin{array}{c}23.24 \pm 1.23^{b} \\
21.1-24.53\end{array}$ \\
\hline STZ-L $(n=9)$ & $\begin{array}{c}17.78 \pm 4.41^{\mathrm{d}} \\
10-20\end{array}$ & $\begin{array}{c}23.37 \pm 1.46^{b} \\
21.66-25.2\end{array}$ \\
\hline$F$ & 49.21 & 18.55 \\
\hline$P$ & $<0.001 * *$ & $<0.001 * *$ \\
\hline
\end{tabular}

F: ANOVA test $\quad * *$ : Highly significant $(\mathrm{P}<0.01)$

Groups with different letters have statistically significant $(\mathrm{P}<0.05)$ differences.

Table (2): LSD for Alternation percentage among the different studied groups

\begin{tabular}{|l|l|l|l|l|l|l|}
\hline & CSF $(\mathrm{n}=6)$ & LV $(\mathrm{n}=6)$ & CSF-LV $(\mathrm{n}=6)$ & STZ $(\mathrm{n}=9)$ & Letrozole $(\mathrm{n}=9)$ & STZ-L $(\mathrm{n}=9)$ \\
\hline Intact $(\mathrm{n}=6)$ & $0.38 \mathrm{NS}$ & $0.56 \mathrm{NS}$ & $0.77 \mathrm{NS}$ & $<0.001^{* *}$ & $<0.001^{* *}$ & $<0.001^{* *}$ \\
\hline CSF $(\mathrm{n}=6)$ & & $0.15 \mathrm{NS}$ & $0.56 \mathrm{NS}$ & $<0.001^{* *}$ & $<0.001^{* *}$ & $<0.001^{* *}$ \\
\hline LV $(\mathrm{n}=6)$ & & & $0.38 \mathrm{NS}$ & $<0.001^{* *}$ & $<0.001^{* *}$ & $<0.001^{* *}$ \\
\hline CSF-LV (n=6) & & & & $<0.001^{* *}$ & $<0.001^{* *}$ & $<0.001^{* *}$ \\
\hline STZ (n=9) & & & & & $<0.001^{* *}$ & $<0.001^{* *}$ \\
\hline Letrozole (n=9) & & & & & & $<0.001^{* *}$ \\
\hline
\end{tabular}

NS: Non significant $(\mathrm{P}>0.05) \quad$ *: Significant $(\mathrm{P}<0.05) \quad$ **: Highly significant $(\mathrm{P}<0.01)$

Table (3): LSD for p-Tau concentration among the different studied groups 


\begin{tabular}{|l|l|l|l|l|l|l|}
\hline & CSF $(\mathrm{n}=6)$ & LV $(\mathrm{n}=6)$ & CSF-LV $(\mathrm{n}=6)$ & STZ $(\mathrm{n}=9)$ & Letrozole $(\mathrm{n}=9)$ & STZ-L $(\mathrm{n}=9)$ \\
\hline Intact $(\mathrm{n}=6)$ & $0.17 \mathrm{NS}$ & $0.43 \mathrm{NS}$ & $0.06 \mathrm{NS}$ & $<0.001^{* *}$ & $<0.001^{* *}$ & $<0.001^{* *}$ \\
\hline CSF $(\mathrm{n}=6)$ & & $0.57 \mathrm{NS}$ & $0.56 \mathrm{NS}$ & $<0.001^{* *}$ & $<0.001^{* *}$ & $<0.001^{* *}$ \\
\hline LV $(\mathrm{n}=6)$ & & & $0.25 \mathrm{NS}$ & $<0.001^{* *}$ & $<0.001^{* *}$ & $<0.001^{* *}$ \\
\hline CSF-LV $(\mathrm{n}=6)$ & & & & $0.001^{* *}$ & $<0.001^{* *}$ & $<0.001^{* *}$ \\
\hline STZ $(\mathrm{n}=9)$ & & & & & $0.29 \mathrm{NS}$ & $0.23 \mathrm{NS}$ \\
\hline Letrozole $(\mathrm{n}=9)$ & & & & & & $0.87 \mathrm{NS}$ \\
\hline
\end{tabular}

NS: Non significant $(\mathrm{P}>0.05) \quad$ *: Significant $(\mathrm{P}<0.05)$

**: Highly significant $(\mathrm{P}<0.01)$

Table (4): Let-7 miRNAs expression (in fold change) in the studied groups

\begin{tabular}{|c|c|c|c|}
\hline Parameter & $\begin{array}{c}\text { Let-7a fold change } \\
\text { Mean } \pm \text { SD } \\
\text { Median } \\
\text { Range } \\
\end{array}$ & $\begin{array}{c}\text { Let-7b fold change } \\
\text { Mean } \pm \text { SD } \\
\text { Median } \\
\text { Range } \\
\end{array}$ & $\begin{array}{c}\text { Let-7e fold change } \\
\text { Mean } \pm \text { SD } \\
\text { Median } \\
\text { Range } \\
\end{array}$ \\
\hline intact $(n=6)$ & $\begin{array}{c}1.30 \pm 1^{\mathrm{a}} \\
0.87 \\
0.46-2.59\end{array}$ & $\begin{array}{c}1.55 \pm 1.34^{\mathrm{a}} \\
1.29 \\
0.2-3.63\end{array}$ & $\begin{array}{c}1.94 \pm 1.74^{\mathrm{a}} \\
1.75 \\
0.9-4\end{array}$ \\
\hline $\operatorname{SSF}(n=6)$ & $\begin{array}{c}1.60 \pm 1^{\mathrm{a}} \\
1.57 \\
0.67-2.57\end{array}$ & $\begin{array}{c}1.8 \pm 1.24^{\mathrm{a}} \\
1.92 \\
0.52-2.99\end{array}$ & $\begin{array}{c}1.56 \pm 0.74^{\mathrm{a}} \\
1.89 \\
0.62-2.36\end{array}$ \\
\hline$\overline{L V}(n=6)$ & $\begin{array}{c}1.35 \pm 0.43^{\mathrm{a}} \\
1.18 \\
0.95-1.9\end{array}$ & $\begin{array}{c}1.52 \pm 0.32^{\mathrm{a}} \\
1.53 \\
1.16-1.88\end{array}$ & $\begin{array}{c}1.70 \pm 1.20^{\mathrm{a}} \\
1.86 \\
0.35-2.91\end{array}$ \\
\hline$\overline{\text { ZSF-LV }(n=6)}$ & $\begin{array}{c}1.26 \pm 2.45^{\mathrm{a}} \\
0.21 \\
0.17-6.25\end{array}$ & $\begin{array}{c}0.84 \pm 0.82^{a} \\
0.43 \\
0.34-2.41\end{array}$ & $\begin{array}{c}1.35 \pm 2.35^{a} \\
0.41 \\
0.11-6.11\end{array}$ \\
\hline รTZ $(n=9)$ & $\begin{array}{c}0.97 \pm 0.84^{\mathrm{a}} \\
0.64 \\
0.06-2.45\end{array}$ & $\begin{array}{c}1.89 \pm 1.41^{\mathrm{a}} \\
1.81 \\
0.39-4.85\end{array}$ & $\begin{array}{c}2.35 \pm 1.60^{\mathrm{a}} \\
2.91 \\
0.47-5.54\end{array}$ \\
\hline Letrozole $(n=9)$ & $\begin{array}{c}4.70 \pm 2.07^{b} \\
5.18 \\
0.8-7.85\end{array}$ & $\begin{array}{c}6.47 \pm 3.39 \mathrm{~b} \\
5.85 \\
1.07-12.37 \\
\end{array}$ & $\begin{array}{c}9.01 \pm 5.12^{b} \\
7.36 \\
2.89-17.27\end{array}$ \\
\hline รTZ-L $(n=9)$ & $\begin{array}{c}5.91 \pm 3.94 \mathrm{~b} \\
4.8 \\
3.1-14.25 \\
\end{array}$ & $\begin{array}{c}5.93 \pm 2.66^{b} \\
4.82 \\
3.16-10.11 \\
\end{array}$ & $\begin{array}{c}9.29 \pm 6.28^{b} \\
7.73 \\
3.2-19.97\end{array}$ \\
\hline$\overline{\mathrm{KW}}$ & 29.89 & 30.24 & 31.35 \\
\hline $\mathrm{P}$ & $<0.001 * *$ & $<0.001 * *$ & $<0.001 * *$ \\
\hline
\end{tabular}

KW: Kruskal Wallis test $\quad$ **: Highly significant $(\mathrm{P}<0.01)$

Groups with different letters have statistically significant $(\mathrm{P}<0.05)$ differences. 
Table (5): LSD for Let-7a fold change among different studied groups

\begin{tabular}{|l|l|l|l|l|l|l|}
\hline & CSF (n=6) & LV (n=6) & CSF-LV (n=6) & STZ (n=9) & Letrozole (n=9) & STZ-L (n=9) \\
\hline Intact $(\mathrm{n}=6)$ & $0.47 \mathrm{NS}$ & $0.63 \mathrm{NS}$ & $0.11 \mathrm{NS}$ & $0.35 \mathrm{NS}$ & $0.005^{* *}$ & $0.001^{* *}$ \\
\hline CSF $(\mathrm{n}=6)$ & & $0.99 \mathrm{NS}$ & $0.06 \mathrm{NS}$ & $0.09 \mathrm{NS}$ & $0.005^{* *}$ & $0.001^{* *}$ \\
\hline LV $(\mathrm{n}=6)$ & & & $0.06 \mathrm{NS}$ & $0.41 \mathrm{NS}$ & $0.01^{*}$ & $0.001^{* *}$ \\
\hline CSF-LV (n=6) & & & & $0.24 \mathrm{NS}$ & $0.02^{*}$ & $0.02^{*}$ \\
\hline STZ $(\mathrm{n}=9)$ & & & & & $0.001^{* *}$ & $<0.001^{* *}$ \\
\hline Letrozole $(\mathrm{n}=9)$ & & & & & & $0.86 \mathrm{NS}$ \\
\hline
\end{tabular}

NS: Non significant $(\mathrm{P}>0.05) \quad$ *: Significant $(\mathrm{P}<0.05) \quad$ **: Highly significant $(\mathrm{P}<0.01)$

Table (6): LSD for Let-7b fold change among different studied groups

\begin{tabular}{|l|l|l|l|l|l|l|}
\hline & CSF (n=6) & LV (n=6) & CSF-LV (n=6) & STZ (n=9) & Letrozole (n=9) & STZ-L (n=9) \\
\hline Intact (n=6) & 0.63 NS & 0.63 NS & 0.75 NS & $0.56 \mathrm{NS}$ & $0.007^{* *}$ & $0.003^{* *}$ \\
\hline CSF (n=6) & & $0.99 \mathrm{NS}$ & $0.06 \mathrm{NS}$ & $0.48 \mathrm{NS}$ & $0.005^{* *}$ & $0.001^{* *}$ \\
\hline LV (n=6) & & & $0.06 \mathrm{NS}$ & $0.56 \mathrm{NS}$ & $0.01^{*}$ & $0.001^{* *}$ \\
\hline CSF-LV (n=6) & & & & $0.08 \mathrm{NS}$ & $0.002^{* *}$ & $0.001^{* *}$ \\
\hline STZ (n=9) & & & & & $0.004^{* *}$ & $0.002^{* *}$ \\
\hline Letrozole (n=9) & & & & & & $0.63 \mathrm{NS}$ \\
\hline
\end{tabular}

NS: Non significant $(\mathrm{P}>0.05) \quad$ *: Significant $(\mathrm{P}<0.05) \quad$ **: Highly significant $(\mathrm{P}<0.01)$

Table (7): LSD for Let-7e fold change among different studied groups

\begin{tabular}{|l|c|c|c|c|c|c|}
\hline & CSF (n=6) & LV (n=6) & CSF-LV (n=6) & STZ (n=9) & Letrozole (n=9) & STZ-L (n=9) \\
\hline Intact $(\mathrm{n}=6)$ & $0.75 \mathrm{NS}$ & $0.99 \mathrm{NS}$ & $0.63 \mathrm{NS}$ & $0.56 \mathrm{NS}$ & $0.003^{* *}$ & $0.01^{*}$ \\
\hline CSF $(\mathrm{n}=6)$ & & $0.75 \mathrm{NS}$ & $0.11 \mathrm{NS}$ & $0.29 \mathrm{NS}$ & $0.001^{* *}$ & $0.001^{* *}$ \\
\hline LV $(\mathrm{n}=6)$ & & & $0.34 \mathrm{NS}$ & $0.18 \mathrm{NS}$ & $0.002^{* *}$ & $0.001^{* *}$ \\
\hline CSF-LV $(\mathrm{n}=6)$ & & & & $0.06 \mathrm{NS}$ & $0.003^{* *}$ & $0.005^{* *}$ \\
\hline STZ $(\mathrm{n}=9)$ & & & & & $0.002^{* *}$ & $0.001^{* *}$ \\
\hline Letrozole (n=9) & & & & & & $0.72 \mathrm{NS}$ \\
\hline
\end{tabular}

NS: Non significant $(\mathrm{P}>0.05) \quad$ *: Significant $(\mathrm{P}<0.05) \quad$ **: Highly significant $(\mathrm{P}<0.01)$

Table (8): Correlations between alternation percentage, p-Tau concentration and Let-7 miRNAs expression

\begin{tabular}{|l|c|c|c|c|}
\hline \multirow{2}{*}{} & \multicolumn{2}{|c|}{ Alternation percentage } & \multicolumn{2}{c|}{$\mathrm{p}$-Tau concentration } \\
\cline { 2 - 5 } & $\mathrm{r}$ & $\mathrm{P}$ & $\mathrm{r}$ & $\mathrm{P}$ \\
\hline Let-7a fold change & -0.36 & $0.01^{*}$ & 0.57 & $<0.001^{* *}$ \\
\hline Let-7b fold change & -0.43 & $0.002^{* *}$ & 0.62 & $<0.001^{* *}$ \\
\hline Let-7e fold change & -0.57 & $<0.001^{* *}$ & 0.64 & $<0.001^{* *}$ \\
\hline p-Tau concentration & -0.72 & $<0.001^{* *}$ & --- & ---- \\
\hline
\end{tabular}

r: Spearman correlation coefficient $\quad$ *: Significant $(\mathrm{P}<0.05) * *$ : Highly significant $(\mathrm{P}<0.01)$ 


\section{Figures}
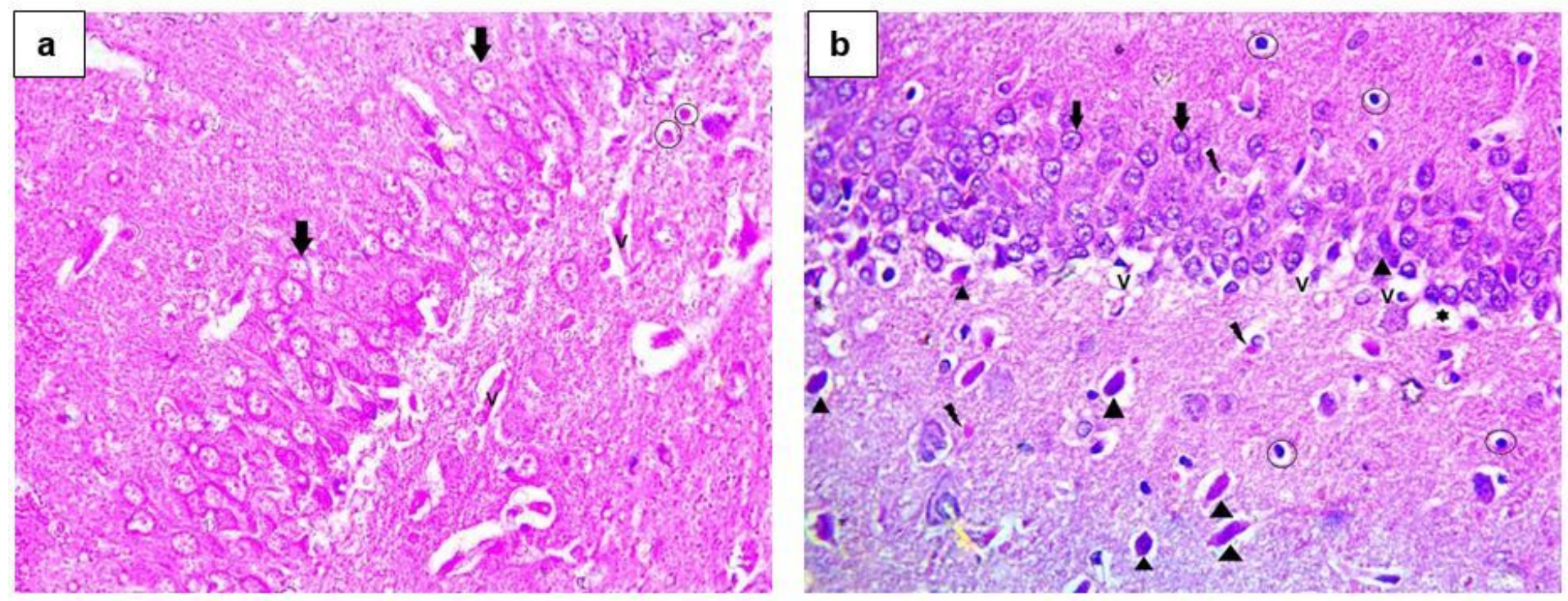

\section{Figure 1}

Sections in the hippocampus

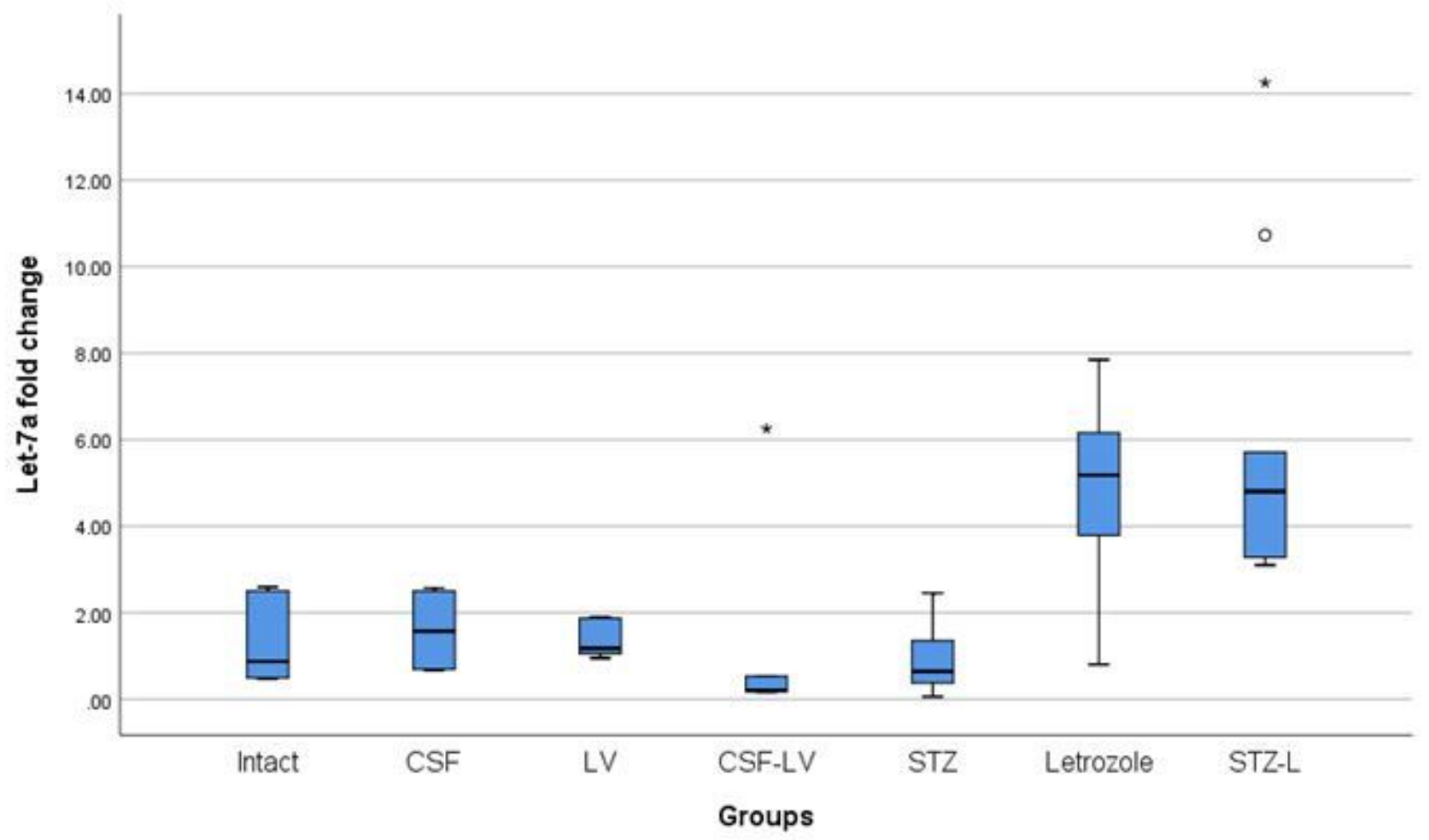

Figure 2

A box plot showing Let-7a fold change among the studied groups 


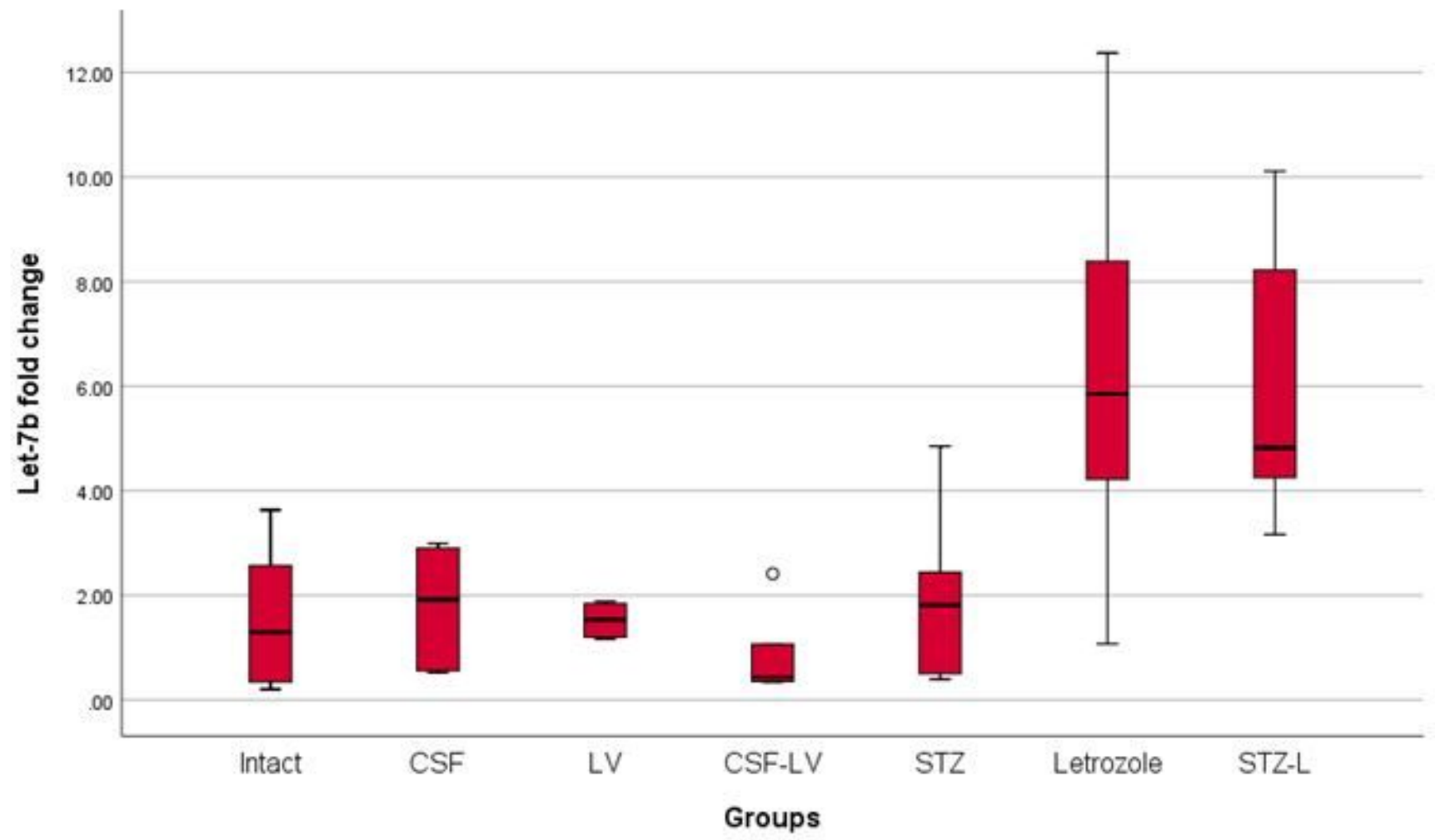

Figure 3

A box plot showing Let-7b fold change among the studied groups

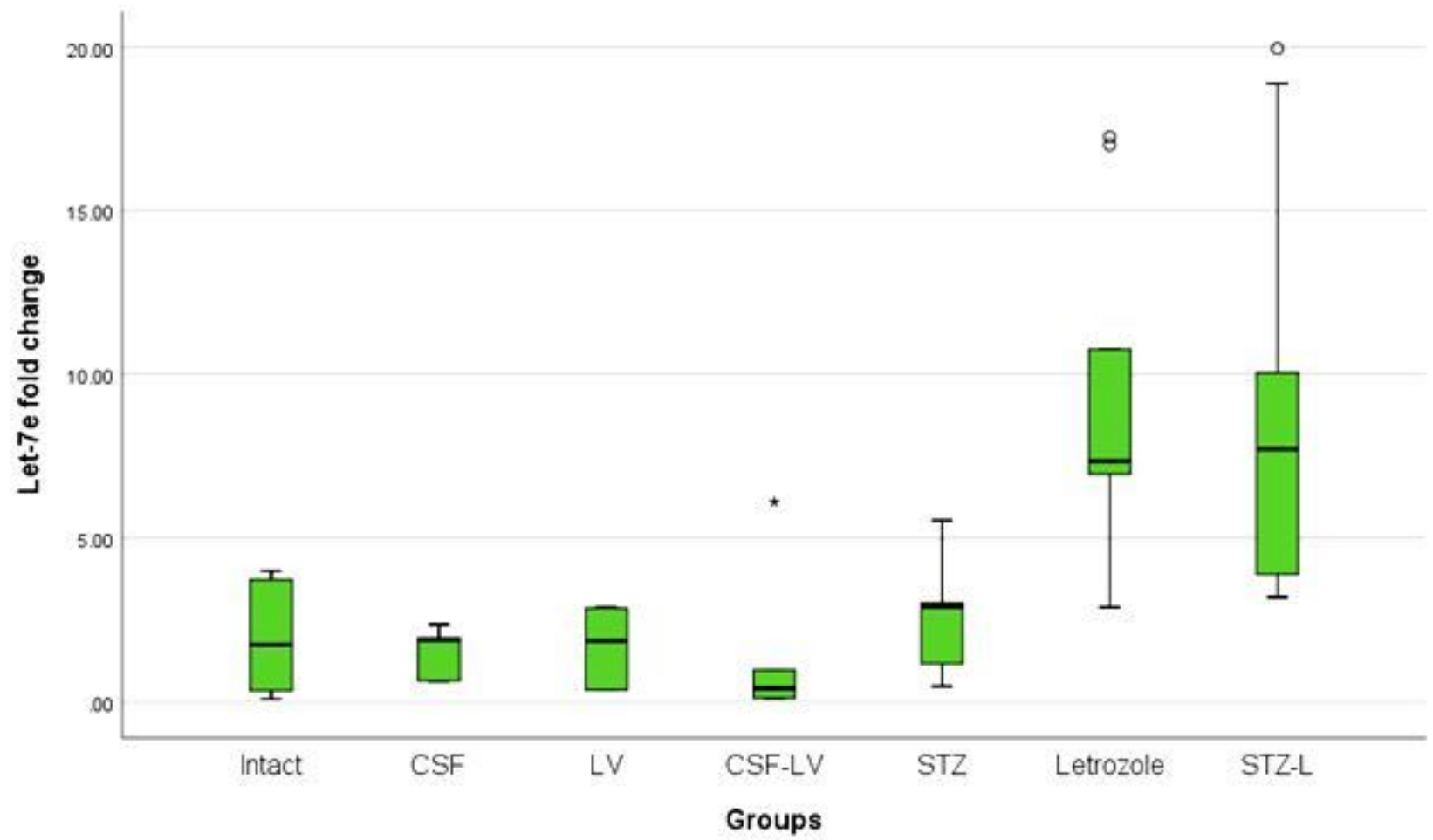

Figure 4 
A box plot showing Let-7e fold change among the studied groups

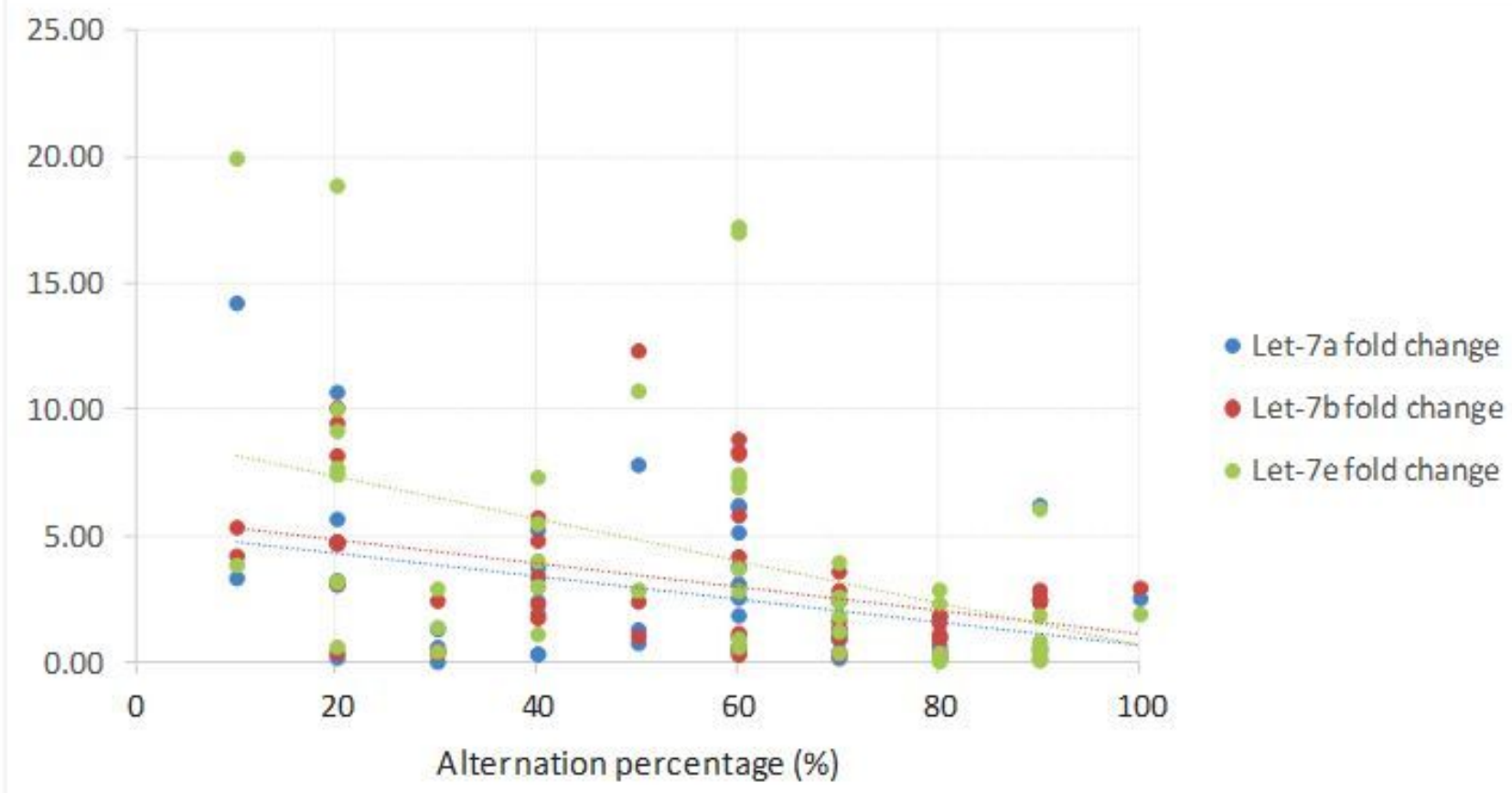

\section{Figure 5}

Correlation between alternation percentage and the fold change of Let-7 miRNAs 


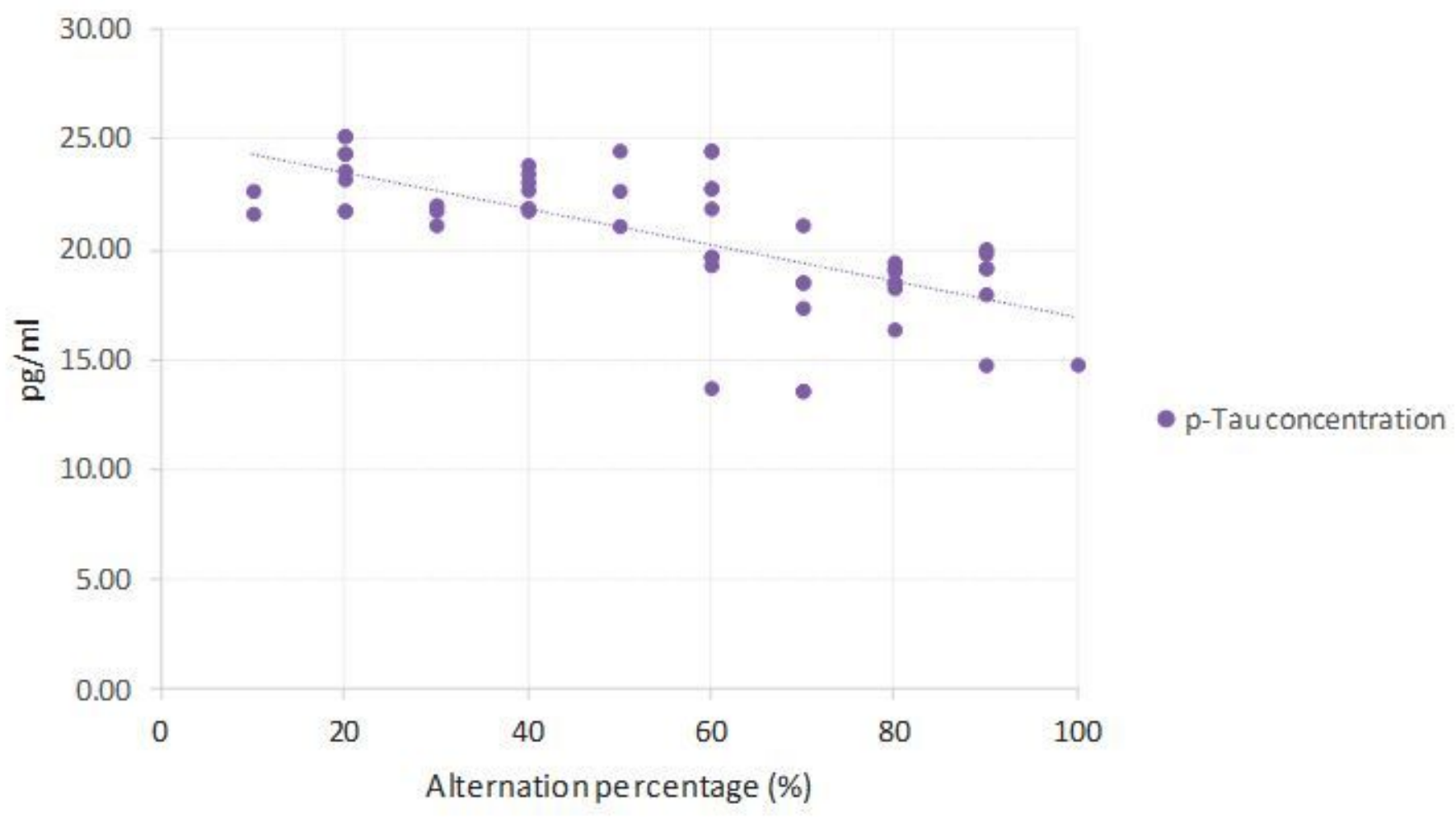

Figure 6

Correlation between alternation percentage and p-Tau concentration

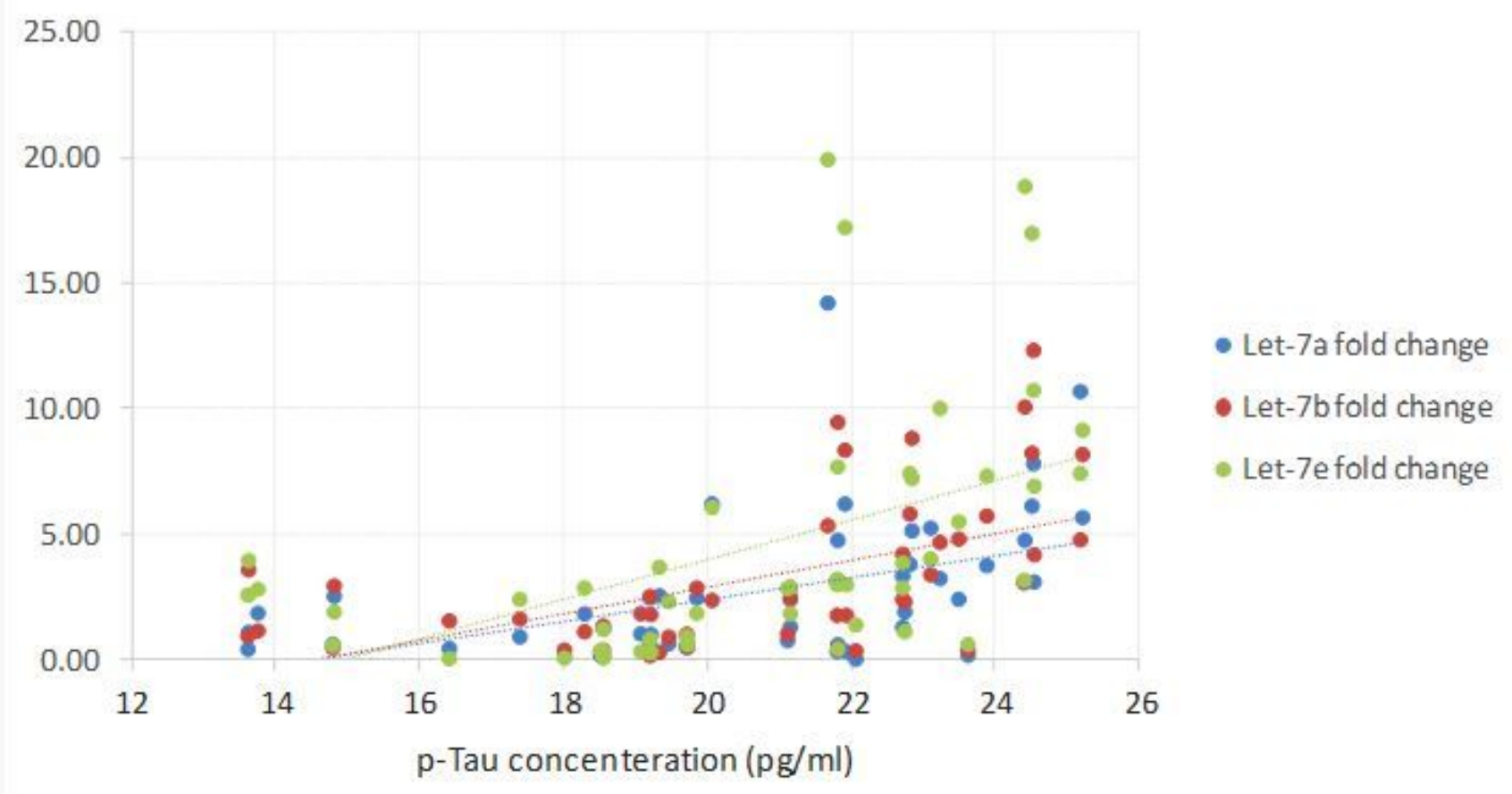


Figure 7

Correlation between $\mathrm{p}$-Tau concentration and the fold change of Let-7 miRNAs

\section{Supplementary Files}

This is a list of supplementary files associated with this preprint. Click to download.

- formula.docx 